\title{
Analysis on the Feasibility of China's "Vendor Economy" under the New Economic Condition
}

\author{
Qing Sun*
}

St. Paul University Manila, 680 Pedro Gil St., Malate, 1004 Manila, Philippines. E-mail: 236993563@qq.com

\begin{abstract}
Vendor economy, also called street economy, which is often considered as the main income sources for street vendors and was regarded as marginal economy, has grown into a type of economic form. From the perspective of total social wealth, it jump-starts the economy, stimulates people's consumption desire and provides more employment opportunities, which drives a sharp increase in social total consumption, according to a research report analyzed from 2007 to 2017 by the Northeast Securities. During the ten years, China's economic policy is to encourage and support street vendors, and because of this, consumption plates are shown in a more obvious rise in profits, but it also has brought about some negative effects. On the basis of the characteristics and roles of the vendor economy, this paper analyzes its feasibility under the new economic condition through the comparison of its advantages and disadvantages. In addition, some suggestions are put forward to Chinese government and the street vendors.
\end{abstract}

Keywords: Vendor Economy; Externality; Feasible Measures; New Economic Condition

\section{Advantages of the vendor economy}

(1) The threshold of the vendor economy is relatively low, as a shop is not a necessity for the vendor economy, its cost will be lower than that of the ordinary real economy, and ordinary people can easily realize the "entrepreneurial dream". Therefore, from this perspective, vendor economy can alleviate the employment pressure of the whole society.

(2) Products of the vendor economy are groceries or small home appliance, such as towels, wash basin, clothing and torches. What is more, the price is affordable, which could meet the basic needs of ordinary consumers, especially for migrant workers, who have lower income and no high purchasing power.

(3) Vendor economy also provides convenient shopping for the old, who live in the city but are not familiar with using the online shopping, such as breakfast or snack stalls, repairing shoes or darning stalls, small commodities or appliances stalls.

(4) The night market in the street provides a relaxing way for workers who work hard during the day, where they can not only learn about the daily life of ordinary people but also taste some special food and snacks or experience some novel entertainments.

(5) Vendor economy is also a good choice of sidelines for people. For example, some white-collar workers who work in the office during the day could set up stalls in their spare time after work in the evening, which may increase their daily income as well.

Copyright (C) 2020 Qing Sun

doi: $10.18282 / \mathrm{ff} . \mathrm{v} 9 \mathrm{i} 2.878$

This is an open-access article distributed under the terms of the Creative Commons Attribution Non-Commercial License

(http://creativecommons.org/licenses/by-nc/4.0/), which permits unrestricted non-commercial use, distribution, and reproduction in any medium, provided the original work is properly cited. 


\section{Disadvantages of the vendor economy}

The essence of the local economy lies in the free access to traffic resources, which is often accompanied by a phenomenon, that is, the "tragedy of the commons"[1]. If there is no control, people will abuse this resource until it is exhausted, meanwhile, making pedestrians or residents bear negative externalities. Economic externality refers to the non-market influence exerted by the economic activities of a certain economic unit on other economic units ${ }^{[4]}$. Non-market influence is concerned with the cost or benefit generated by an activity that cannot be reflected via market prices but is unconsciously imposed on others ${ }^{[4]}$. Externality consists of positive externality and negative externality. Positive externalities are considered as an economic main body, which has a good impact on other economic subjects or free to benefit others, such as positive externality of repairing the historic building, as people who live in these buildings can enjoy the beauty of these buildings and understand the connotation of history from the heart when they take a walk or ride a bike. On the other hand, negative externality are usually regarded as the negative impact on other economic units and the cost imposed on others ${ }^{[4]}$, for example the neighbor talks loudly at 2 am or sing or play musical instruments, the customer who is sitting next to you smokes in a restaurant, or people have to breathe the automobile exhaust. Externality is an apparent feature of attention ${ }^{[2]}$, but not in the sale of goods on the market. The problem is caused by lack of external market, which causes differences between the personal behavior and needs of society, and between the private cost and social cost. Private cost could often be thought as the cost an economic unit need to pay in a certain economic activities, while social cost is concerned with the whole society to a certain activities, including in the economic activities of the private cost plus the cost of this activity to other economic units ${ }^{[3]}$. If the social cost produced by the negative externality of economic activity is greater than the private cost, in contrast, if this economic activity has a positive externality, it means that the social cost is less than the private cost. For example, in steel factories, for every ton of steel produced, a certain amount of smoke and dust enters the atmosphere. Due to the threat of pollutants to human health, the social costs per unit of steel produced include the private costs of steel producers and the costs of bystanders adversely affected by pollutants. Hence, from this perspective, it has negative externalities, as the social cost of steel production is greater than the private cost of steel producers.

As vendor economy is based on the road or piazza, its emergence will also produce corresponding negative externalities. For example, in the subway passage, if there are so many street vendors, it will make the space narrow for pedestrians and so is the subway entrances. Moreover, drivers have to slow down and pass slowly, which also increases the probability of traffic accidents. What is more, if there is too much noise or too many people have midnight snacks every day outside ordinary communities, it will cause noise pollution and environment pollution, which will bring serious negative results to residents' daily life.

\section{Feasible measures}

(1) In terms of traffic and noise issues, the traffic administration could first divide the vendor area and time, and then standardize the order of parking and stall covers.

(2) As for the environmental problems, the local government could make rules or regulations for vendors to obey. If they break them they will be punished. For example, street vendors should be run their own stall in the health area, if they have much waste around them they should be charged; or they can ask some cleaning companies for help by paying them some money. Moreover, the local government could also follow the exemplar of western countries, namely, making vendors pay pollution tax, which is called Pigou Tax ${ }^{[5]}$. The formula to calculate is shown below, if $\mathrm{MB}=300-\mathrm{Q}$, $\mathrm{MPC}=20+\mathrm{Q}, \mathrm{MD}=40+2 \mathrm{Q}, \mathrm{t}=\mathrm{MD}$. Meanwhile, $\mathrm{t}=160$, what is result of the effective equilibrium yield?

The result could be shown as following:

$$
\begin{aligned}
& \mathrm{MB}=\mathrm{MPC}+\mathrm{t} \\
&=20+\mathrm{Q}+\mathrm{t} \\
&=20+\mathrm{Q}+160 \\
& 300-\mathrm{Q}=180+\mathrm{Q}
\end{aligned}
$$


(3) In regard to the issue of food safety, the local health and epidemic prevention departments could make regular spot checks and inspections at times.

(4) For products or services quality problems, it is necessary to set up special departments for consumer complaints or dispute settlement and organize personnel to conduct spot checks and inspections regularly.

As private vendors, they should realize that vendor economy is also a form of the self-media in "brick economy". If they want to sell products or provide services, the first thing they should consider is the location. As mentioned above, the essence of vendor economy is sharing population flow. Hence, from this perspective, it is very crucial for vendors to choose places of their stall, such as outside schools or near dancing squares. The second is to pay close attention to their quality and price of their products or services, which should be affordable and of high quality. Because online shopping is very convenient and cheap currently, if the products or services that they provide are not good enough, it will difficult for them to attract regular customers. On the other hand, online economy has a set of relatively scientific and perfect system, so as street vendors, they have to make a reasonable price and good quality of their products or services, especially, with timely and patient after-sales service. Another point is the selection of goods. The stall owners also need to make the products novel, namely, making their products as "web celebrity", so as to realize dislocation competition and increase the popularity of their stalls. Again, customers information should be collected, such as inviting consumers to a WeChat group, which can combine their own customers together in a community, forming a potential "closed-loo" consumption ${ }^{[6]}$. If the products are of good quality and affordable, the members of the group will introduce more friends or colleagues into the group, so as to realize "snowball effect" and the "closed-loop" consumption also will be bigger and bigger. As a stall owner, he or she had better update the types or functions of the commodities in time as well, such as interactive communication with customers in the form of live broadcast, or organizing group members to regularly share the usage experience of the commodities in the stall. The sharing mode can be a combination of online introduction and offline interaction.

The Chinese government, who can make a plan to carry it out rather than use the traditional pattern of "one size fits all"[7]. For instance, from the perspective of district issue, the core business district, high-grade residential areas or villas don't need vendor economy, whereas, some old districts need them. Thus, as the competent department, they should formulate and take specific measures according to the actual needs of people in different districts. For example, just like Japan, the state allows people to have street economy, but it is merely in some special festivals. The purpose of this commercial activity is to enhance the festive atmosphere.

In all, due to the deep and widespread sense of uncertainty, the economy of the global is weakening, and so is China. Vendor economy, as a typical exemplar of new kind of economic model, needs to keep pace with times. For instance, the online and offline sale should be combined, so as to provide more diversified products or services with high quality.

\section{References}

1. Briner B. The management methods of Jesus. Nashville, Thjomas Nelson; 1996.

2. Feinberg M, Tarrant JJ. Why smart people do dumb things. New York: Simon and Schuester; 1995.

3. Goleman D. Emotional intelligence. New York: Bantam/Dell; 2006 [1995].

4. Yu N. Microsoft economy. Version 1. QunYan Press; 2018; p. 291-293.

5. Pigou AC. Welfare economics. 1920.

6. Collins J. Good to great. New York: Harper Collins; 2001.

7. Kets De Vries M, Miller D. Unstable at the top. New York: New American Library; 1987. 